\title{
Interfaceando com o Espectro Autista
}

\author{
Maria Renata M. Gobbo \\ Programa de Pós-Graduação em \\ Ciência da Computação da UEL \\ Londrina, Brasil \\ mr.gobbo1@gmail.com
}

\author{
Cinthyan R. Sachs C. Barbosa \\ Programa de Pós-Graduação em \\ Ciência da Computação da UEL \\ Londrina, Brasil \\ cinthyan@uel.br
}

\author{
Fernanda Mafort \\ Programa de Pós-Graduação em \\ Análise do Comportamento \\ Aplicada da PUC-Londrina \\ fernanda-mafort@hotmail.com
}

\section{RESUMO}

Crianças com Transtorno no Espectro Autista (TEA) apresentam, em algum grau, déficits na comunicação, comportamento e interação social. Jogos têm sido utilizados para ajudá-las nessas questões. Porém, pouca atenção é dada na alfabetização de crianças com TEA e isso reflete também nos jogos com esse propósito. Conceitos de acessibilidade e design interativo são deixados de lado na interação entre usuários autistas e tais aplicativos, o que acaba prejudicando a eficácia dos jogos, principalmente na questão da alfabetização. Este trabalho aborda o desenvolvimento de um jogo que foi criado não apenas para alfabetizar crianças no espectro autista, mas também para familiarizá-las com atividades de autocuidado e higiene pessoal (chamadas de Atividades de Vida Diária - AVDs), através de PECS (Pictures Exchange Communication System).

\section{Palavras-chave}

Transtorno do Espectro Autista; Jogos para Educação Especial; Acessibilidade.

\section{ACM Classification Keywords}

Software; Human-computer interaction; Applied Computing; Education.

\section{INTRODUÇÃO}

Ler é um fator imprescindível para o desenvolvimento da capacidade de compreensão leitora. Quanto mais se pratica a leitura, mais se acumula o vocabulário e a atenção do leitor fica cada vez mais voltada para o significado do texto [1].

O Transtorno de Espectro Autista (TEA) é uma condição do neurodesenvolvimento que se manifesta de várias maneiras: falta de habilidade social e de comunicação, padrões de pensamento e comportamentos repetitivos [2].

Antes de começar alfabetizar as crianças com TEA é necessário ensinar as habilidades rudimentares de leitura,

Permission to make digital or hard copies of all or part of this work for personal or classroom use is granted without fee provided that copies are not made or distributed for profit or commercial advantage and that copies bear this notice and the full citation on the first page. Copyrights for components of this work owned by others than the author(s) must be honored. Abstracting with credit is permitted. To copy otherwise, or republish, to post on servers or to redistribute to lists, requires prior specific permission and/or a fee. Copyright 2018 SBC.

IHC 2018, Anais Estendidos do XVII Simpósio Brasileiro sobre Fatores

Humanos em Sistemas Computacionais

Outubro 22-26, 2018, Belém, Brasil

PÔSTERES VIRTUAIS E DEMOS que dizem respeito ao emparelhamento de palavras impressas, nomeação de figuras, vogais, consoantes e sílabas simples [3]. Caso o educando não consiga realizar essas habilidades é necessário ensiná-lo antes de começar o processo de alfabetização. As atividades mostradas a seguir foram as recomendadas por Gomes [3].

O objetivo deste trabalho foi o desenvolvimento de um jogo para a alfabetização de pessoas com TEA com o intuito de familiarizá-las com as atividades de autocuidado através de PECS (Pictures Exchange Communication System).

\section{DESENVOLVIMENTO DO JOGO}

$O$ jogo de alfabetização utiliza PECS relacionadas às Atividades de Vida Diária (AVDs) dessas crianças, pois muitas crianças com TEA têm dificuldades de relacionar objetos com seus nomes [3]. Isso acaba gerando uma leitura sem compreensão. As AVDs dessas crianças se referem principalmente às atividades básicas realizadas por indivíduos como [4]: higiene pessoal, alimentação, comunicação, mobilidade, controle do ambiente e vestuário.

Em casos de autismo mais severos o desenvolvimento das habilidades de vida diária acaba se tornando mais importante do que a aquisição de leitura, pois a independência dessas pessoas se torna imprescindível para terem uma qualidade de vida melhor. Um dos diferenciais do jogo é alfabetizar enquanto são ensinadas AVDs que precisam ser realizadas diariamente de forma independente.

Todas as fases do jogo foram baseadas nas técnicas de alfabetização descritas em [3]. A nomeação de figuras e vogais é uma atividade fundamental para a leitura. Essa habilidade de nomeação é importante para o aprendiz relacionar o som à palavra escrita e também ao seu significado.

\section{Níveis}

O primeiro nível do jogo foi baseado na nomeação de imagens. Isso ocorreu através do emparelhamento de imagens. Estímulos (som/figura/palavra) foram utilizados. O som (áudio) sempre vem com a figura e a palavra, bastando apenas a criança clicar em cima das mesmas. Através do áudio a criança poderá ouvir, aprender e, quando adquirir segurança ou a articulação fonoaudiológica necessária naquela palavra pode começar a pronunciá-la.

Entender o significado da palavra e relacionar com o seu som é fundamental para o desenvolvimento da leitura com compreensão [5]. Muitas pessoas com TEA conseguem ler 
uma palavra, mas não conseguem fazer a relação dessa com o significado no mundo real.

A criança deverá emparelhar as figuras idênticas para mudar de nível (Figura 1), arrastando a(s) imagem/imagens de um lado da tela para o outro. Ao clicar sobre essa instantaneamente será reproduzido o som correspondente.

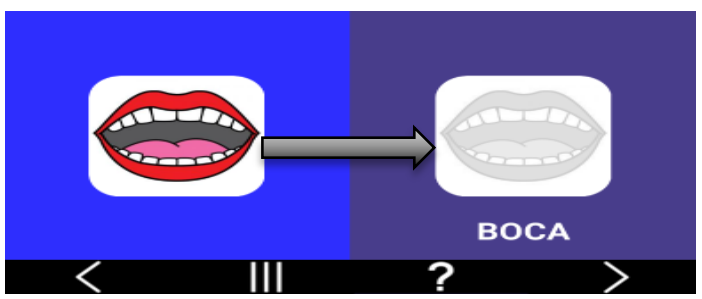

Figura 1. Exemplo do nível 1.

No nível 2 é utilizado o emparelhamento multimodelo, onde serão apresentadas três figuras diferentes, as quais deverão ser arrastadas de um lado da tela para seu lugar correspondente. Tal nível conta com 50 figuras, que utilizam de pictogramas contendo as AVDs (Figura 2). Essas imagens foram retiradas do portal ARASAAC (Portal Aragonês de Comunicação Aumentativa $e$ Alternativa) que disponibiliza gratuitamente imagens prontas para a criação de pranchas de comunicação alternativas.

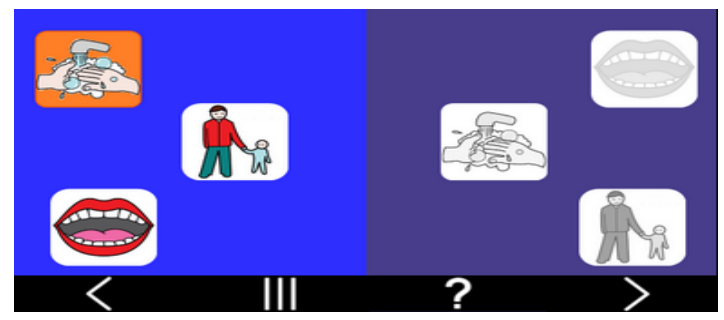

Figura 2. Exemplo do nível multimodelo.

Todas as letras do alfabeto serão ensinadas na fase 3, fazendo com que a criança tenha consciência fonológica dessas. É possível ver a palavra escrita por inteiro (Figura 3). A letra que está faltando se localiza no lado esquerdo da tela e deve-se clicar sobre essa, arrastando-a até o outro lado.

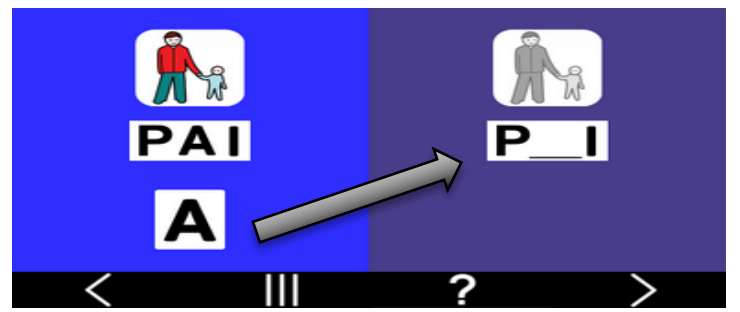

Figura 3. Exemplo do nível 3.

No jogo foi seguido o método fônico [6] que orienta o ensino de letras na seguinte sequência: A, E, I, O, U, F, J, M, N, V, Z, L, S, R, X, B, C, P, D, T, G, Q, H, K, Y e W. Isso é feito para que haja uma regularidade durante o desenvolvimento das famílias silábicas.
O nível 4 é bem semelhante ao 3, porém no lugar das letras do alfabeto serão as sílabas. No nível 5 (Figura 4) a criança deverá emparelhar a palavra correspondente à figura, a fim de verificarmos se ela consegue entender o seu significado, além de ler a palavra escrita.

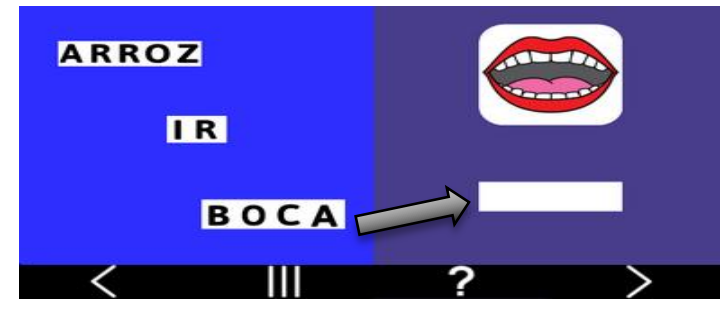

Figura 4. Exemplo do nível 5.

Os níveis irão sendo desbloqueados conforme a criança for avançando por um determinado grupo de imagens/palavras.

\section{CONCLUSÕES E TRABALHOS FUTUROS}

Para realizar a alfabetização, no lugar de palavras comuns como "pato", "dedo", etc. foram utilizadas palavras relacionadas às AVDs das crianças, através do método fônico. Assim, além de serem alfabetizadas, aprenderão a rotina que devem realizar de forma independente.

Mesmo sem ter sido testado com usuários finais, o jogo apresentado foi baseado em metodologias científicas estabelecidas para crianças com TEA, como o é o caso do método TEACCH e ABA (Applied Behaviour Analysis).

\section{REFERÊNCIAS}

1. Caroline M. T. De Sampaio e Gislene F. De Oliveira. 2017. Desafio da Leitura e da Escrita em Crianças com Perturbação do Espectro do Autismo. Id on Line Revista Multidisciplinar e de Psicologia. 11, 36: 343362.

2. Christopher Frauenberger, Julia Makhaeva and Katharina Spiel. 2017. Interaction Design and Autistic Children. In: Proceedings of the Conference on Interaction Design and Children (ACM), 743-748.

3. Camila G. S. Gomes. 2015. Ensino de leitura para pessoas com autismo. Appris.

4. Kevin M. Ayres, Linda Mechling and Frank J. Sansosti. 2013. The use of mobile technologies to assist with life skills/independence of students with moderate/severe intellectual disability and/or autism spectrum disorders: Considerations for the future of school psychology. Psychology in the Schools. 50, 3: 259-271.

5. Camila G. S. Gomes. 2012. Aprendizagem relacional, comportamento simbólico e ensino de leitura a pessoas com transtornos do espectro do autismo. Tese de Doutorado, Universidade Federal de São Carlos, São Carlos, SP.

6. Alessandra G. Seabra e Fernando C. Capovilla. 2004. Alfabetização: método fônico. São Paulo: Memnon. 